\title{
BREAKDOWN OF TRACTOR PARTS IN GHANA: THE CASE OF GHANA HEAVY EQUIPMENT LIMITED (GHEL)
}

\author{
Kutsanedzie Felix ${ }^{1}$, Ofori Victoria ${ }^{2}$, Agyare Anthony Wilson ${ }^{3}$ \\ ${ }^{1}$ Research and Innovation Department, Accra Polytechnic, Accra - Ghana \\ ${ }^{2}$ Agricultural Engineering Department, KNUST, Kumasi - Ghana \\ ${ }^{3}$ Agricultural Engineering Department, KNUST, Kumasi - Ghana
}

\begin{abstract}
Tractor breakdown can be very costly due to loss of work. The objective of this study was to identify tractor parts that frequently broke down; determine the readily availability of spare parts; cost of repairs and whether clients are provided with guidelines. The focus of study was on Ghana Heavy Equipment Limited of which two branches (Accra and Tamale) were used to collect data for the study. Data was collected using questionnaires and written job cards from company. The study showed that the company dealt with Zetor tractors because of its durability and availability of spare parts. The study also indicated that the oil seals, clutch master cylinder, hub bearing and clutch system break down frequently. The study showed that cost of spare parts for servicing and repairs were higher in Tamale than in Accra and this might be due to transportation. It was therefore recommended that operators should not over work machine capacity; and adhere to manufacturers and operators manuals to minimize breakdown. In order to minimize and reduce cost of repairs, tractor operators should service their tractors regularly to increase the life span of the tractor.
\end{abstract}

Keywords: tractors, heavy equipment, breakdown, maintenance, repairs

\section{INTRODUCTION}

Ghana still remains an agricultural based country since majority of its work force are employed in the agricultural sector. Agriculture is central to the government's efforts and accounts for a third of the country's GDP and employs nearly 60 percent of the workforce International Food Policy Research Institute [1]. The sector has seen improvement over the years from the early times where agricultural heavily depended on the use of tools like hoes and cutlasses to produce food for a low population to contemporary times where as a result of providing food for the teeming population of the country and also raw materials for the ever expanding agro based-industries, have resorted in the use of heavy equipment and implements such as tractors.

Food production for the teaming world's population can be achieved through mechanization. It has been done in such other countries like in China [2] and in Oman [3].

Mechanization of agriculture helped transform American agriculture from the situation where one farmer fed 5 people in 1880 to that where one farmer could feed 80 people in 1982 [4]. According to [5], many African countries have abundant agricultural land relative to labour, yet their agriculture is characterized by low productivity for both land and labor. However, in recent years, the pace of intensification in agricultural production has started to increase in Ghana. Tractors are mostly imported from overseas by companies and sold to farmers and other entrepreneurs engaged in agricultural work. The cost of buying these equipment are high and therefore unaffordable to most farmers. [6] reported that the early push for mechanization in Africa failed largely due to the lack of demand, such failure is also due to the government's direct intervention in the supply of mechanization services, which resulted only in low efficiency and high costs without sustainability. Moreover, since these equipment were not designed for our terrain some parts of the equipment are more prone to breakdowns than others. In addition, the maintenance culture of these equipment can result in the frequent breakdown of the whole equipment or parts of it as indicated by [1] that the inefficient machine rental markets in Africa relate to the high maintenance costs of tractors imported by the government without properly developing a repair market with right spare supply.

According to [7], tractor breakdown can be very costly due to loss of working. Moreover, repairs of broken down tractors are also expensive [8]. This is because the breakdown consumes resources, manpower, and spare parts, while production is lost [9]. Poor maintenance or lack of skilled operators result in frequent breakdowns [10]. A few decades ago, research by [11] identified the same problems in Nigeria and recently, [12] reported similar issues in Riau province of Indonesia. In Ghana, the first boost to agricultural mechanization took place after independence in 1957 when the new government offered highly subsidized mechanized services to farmers [13]. However in Ghana, lack of skilled tractor operators is a major constraint to mechanization. Poorly operated tractors result in frequent breakdowns and in shorter lifespans. This makes tractors expensive to operate [14]. 
There are companies that specialize in the repair and servicing of these heavy farm machinery and implements (tractors). One of the largest of these is the Ghana Heavy Equipment Limited (GHEL). It is a limited liability company wholly owned by the Government of Ghana. Its main business has been in the sales and services of earth-moving equipment and agricultural machinery which spans over three decades. Its mission is to provide reliable equipment and excellent after-sales services to all sectors of the economy particularly the mining, construction and agricultural sectors. The Company has branches four branches strategically located in Accra, Kumasi, Obuasi and Tamale.

Ghana Heavy Equipment Limited (GHEL) has been serving and repairing agricultural equipment and implements (tractors) for over thirty years and would have database which can be collected and subjected to analysis to reveal parts of the tractors that suffer breakdowns frequently and the necessary precautions that should be adopted to minimize such occurrences in order for the farmer or the entrepreneur to save money and make farming more profitable.

\subsection{Problem Statement}

In contemporary times agriculture depends heavily on the use of equipment and implements. These however can be acquired at high cost and therefore the need for regular maintenance and servicing is vital. These tractors are mostly made overseas and may not adequately suit the terrain of the country. Some parts of the tractor may be prone to damages than others. Hence the need to identify these parts and recommend the necessary precautions to be taken to minimize their damage.

\subsection{Objectives of the Study}

The primary objective of the study was to find out the most frequently broken down parts of tractors; identify tractor parts that frequently breakdown; determine the availability of spare parts; ascertain the cost of repairing the frequently broken parts; determine whether clients are given guidelines and if guidelines are followed.

\section{MATERIAL AND METHODS}

\subsection{Study Area}

Though there were many agricultural equipment repairing, maintenance and servicing centres dotted all over the country, the Accra and Tamale Branch of Ghana Heavy Equipment Limited (GHEL) were chosen as site for the study. This is because Ghana Heavy Equipment Limited (GHEL) is the foremost company that was established by the Government of Ghana and mandated to supply, repair, maintain and service heavy agricultural equipment like tractors to farmers and other entrepreneurs in the field of agriculture, and therefore well positioned to provide data on tractor parts that frequently breakdown in the country.

\subsection{Materials}

Closed ended questionnaires were designed for targeted respondents (technicians, Supervisors, mechanics and electricians) that focused on the background information of GHEL, servicing and repairing of tractors, parts that frequently breakdown, availability of spare parts and guidelines given to clients (operators). Also job cards which had detailed information on cost associated with repairs, work carried out by Engineers and work requested by clients were evaluated.

\subsection{Questionnaire Design}

A structured questionnaire was designed for the collection of data from the respondents, focused on background information of the company which included the types of tractors the company deals in, their reasons for dealing with those types of tractors/ brands of tractors, the most purchased brand, the type of services they provide and number of Engineers they have to repair or service a tractor. The questionnaires also looked at servicing and repairs of tractors to other tractors bought from other companies, mileage at which tractors are serviced after purchasing, time taken for tractors to be serviced and repaired and cost of servicing the tractors. Others were parts that frequently breakdown, reasons for the frequent breakdown, how long it takes to repair these parts, availability of spare parts and how the company obtains its spare parts. Lastly the questionnaire looked at guidelines given to clients, how they are given, most effective guideline, who provides them and if clients are monitored.

\subsection{Data Collection}

Secondary data was collected using written job cards for information on repairs, maintenance and servicing of agricultural tractors. The job cards contained detailed information on cost of repairs which includes labour charges, cost of spare parts and cost of petrol, oil and grease. The job card also contained work carried out by Engineers and technicians, work requested by clients, mileage and date at which the tractor was brought for servicing or repairs, make of tractor, model ,chassis number, name of client and spare parts used to carry out servicing or repairs ( description, quantity and selling price of spare parts ). In all job cards were evaluated covering 2007 to 2013 of work done by the company. Questionnaire designed were pre-tested and corrections made based on the response. The final questionnaire was then administered to respondents. Answered questionnaires from respondents as well as secondary data from the company from the company were collected and subjected to analysis.

\subsection{Data Analysis}

Secondary data (written job cards) from the Accra and Tamale branches of Ghana Heavy Equipment Limited (GHEL), were collected and statically analysed. Additionally administered questionnaire to targeted respondents at both branches of the company were analysed. The Statistical Software for Social Scientist (SPSS) was used for the 
analysis. The analysis involved descriptive statistics using frequency, percentage and mean response. The processed data was summarized using qualitative tools such as tables and graphs, and the results were then discussed and findings contextualized.

\section{RESULTS AND DISCUSSION}

\subsection{Bio-Data of Respondents}

Survey conducted on the bio-data of respondents indicated that most of the respondents interviewed were supervisors with majority being males and mostly have tractor repair and and 2. working experience of about 1-5 years. Background Information of GHEL

The background information of GHEL indicated that they mostly deal with Zetor tractors and it is because of its durability, capacity and availability of spare parts for servicing and repairs. This thus confirms reports of [1] that spare parts supply market of most of these equipment are unavailable in the country. The company provides sales, services and repairs only to Zetor tractors and has about 1-5 Engineers to work on a tractor as illustrated in Fig. 1.
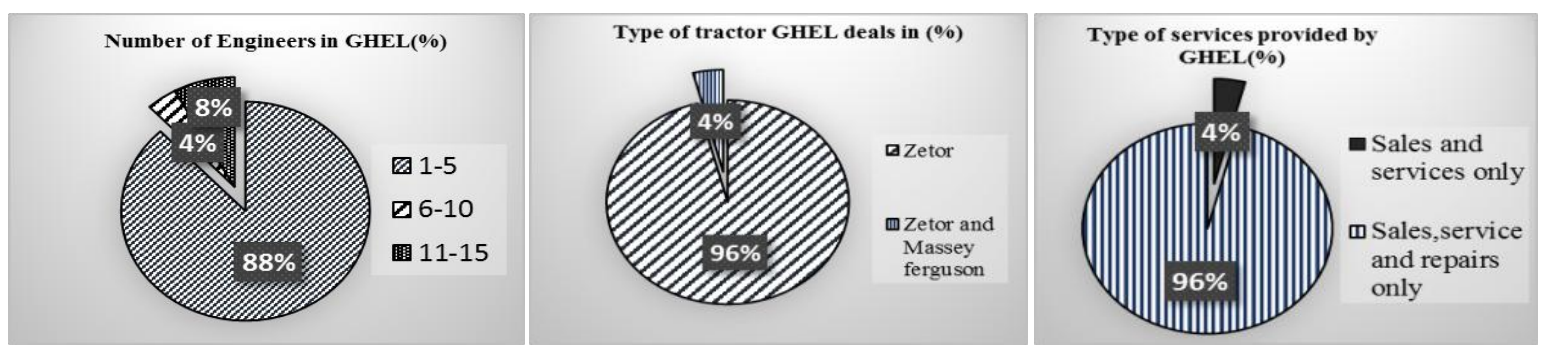

Fig. 1: Type of tractor GHEL deals in, B; Number of engineers in GHEL, C; Types of service provided by GHEL, C

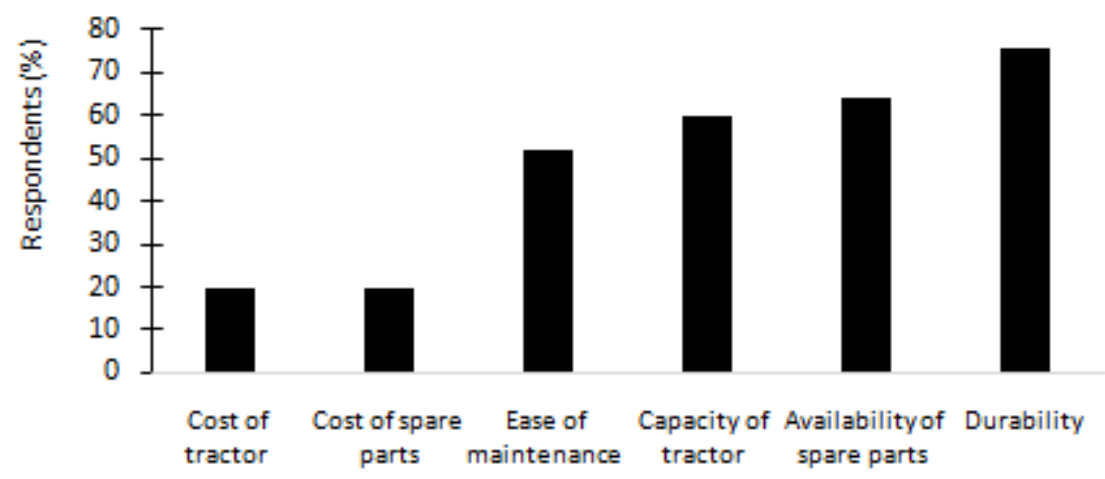

Fig. 2: Reasons GHEL deals with Zetor tractors

\subsection{Servicing and Repairs of Tractor}

Survey conducted indicated that GHEL provides services to tractors bought from other companies and also tractors are usually brought for servicing at every $250 \mathrm{hrs}$ of work. Respondents interviewed also stated that clients bring their tractors for servicing at the required mileage and it takes approximately 2 hours to service tractors. Cost of servicing tractor is moderately high as shown in Fig. 3, 4 and 5. This agrees with [1] that since the spare parts market is not well developed cost of buying this spares are likely to be expensive and thus make tractors expensive to operate [14].

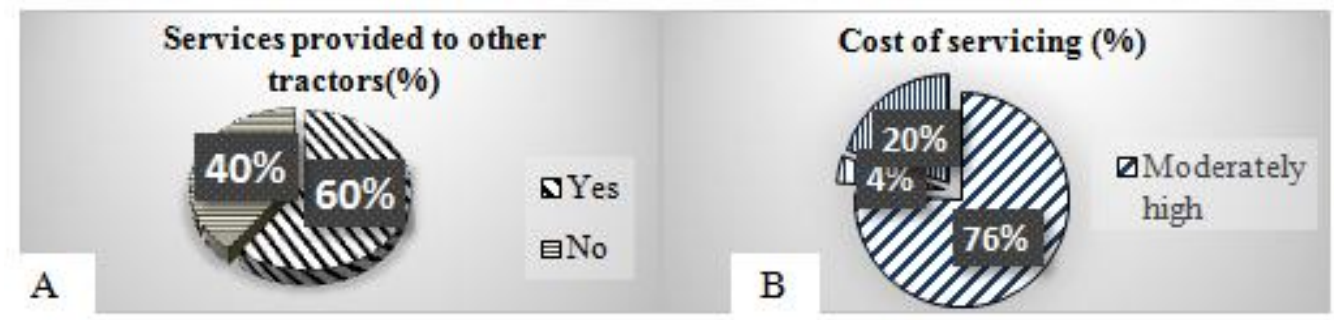

Fig. 3: A; Provision of services to other tractors bought from other companies, B; Cost of servicing 


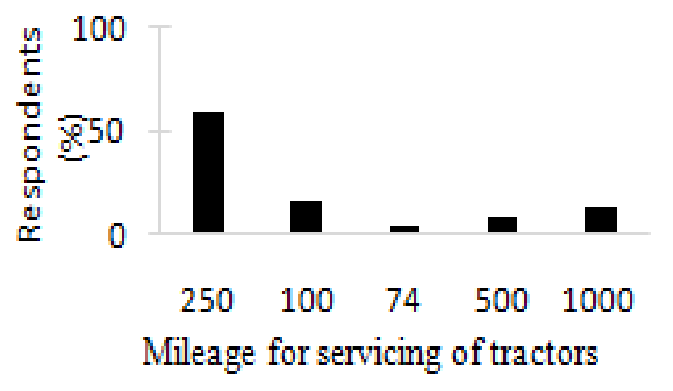

Fig. 4: Mileage at which tractors are brought for servicing

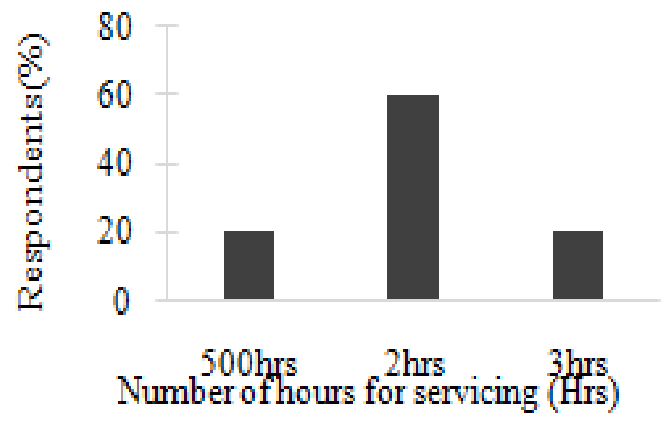

Fig. 5: Number of hours for servicing a tractor

\subsection{Frequently Broken Down Parts}

Interview conducted on parts that frequently breakdown showed that the oil seal, clutch master cylinder, hub bearing, clutch system, braking system, clutch port and break port broke down frequently and also parts that were changed frequently were the air and fuel filter. Reasons these parts breakdown were due to operators over working machines capacity, not adhering to manufacturers and operators manual and improper maintenance. They also indicated that it took 1-3 days to repair tractors as illustrated in Fig. 6 and 7.

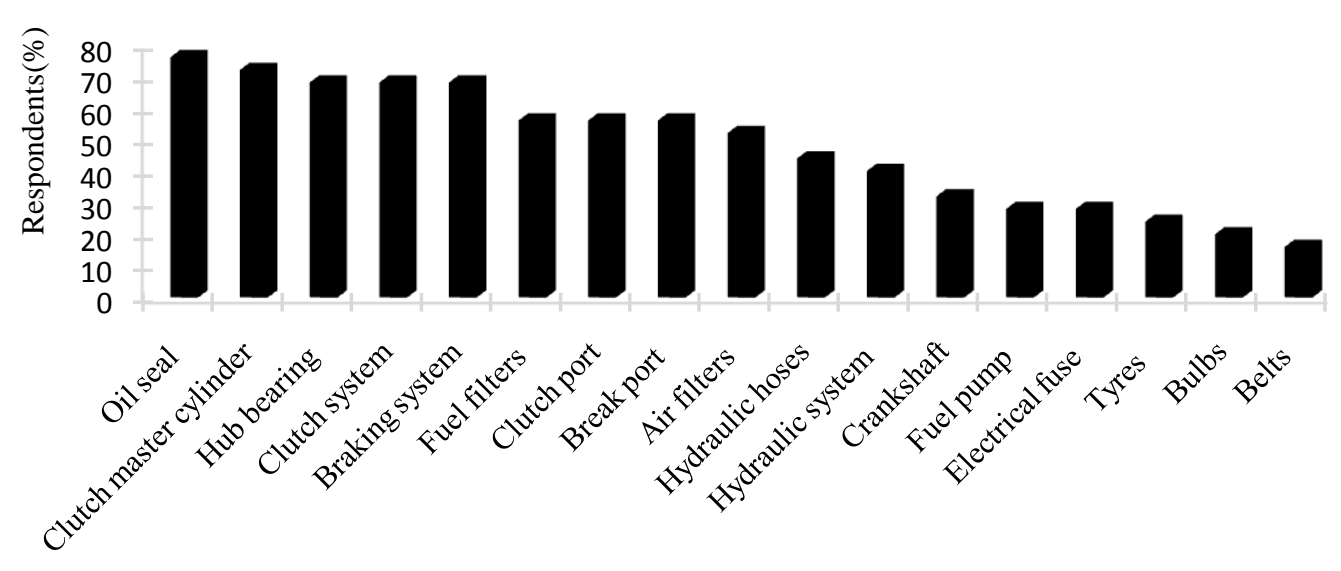

Fig. 6: Parts that frequently breakdown

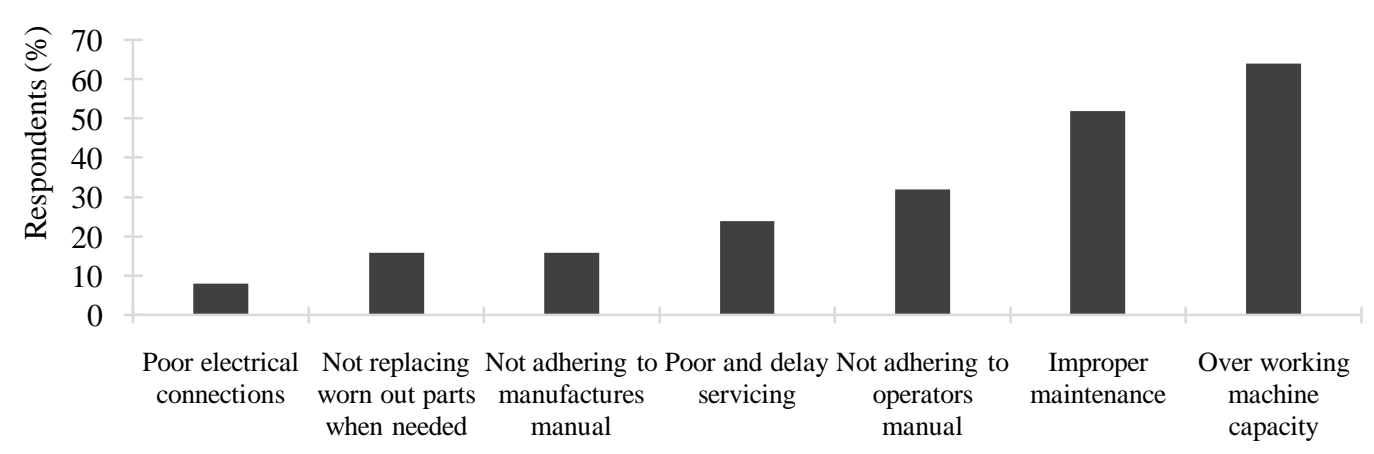

Fig. 7: Reasons parts frequently breakdown

\subsection{Availability of Spare Part}

Respondents interviewed indicated that spare parts are available for repairs and servicing and the company obtains its spare parts mainly by importation which takes approximately 4-6 weeks to be obtained and the cost of these parts are generally moderately high as well as cost of repairs as indicated in Fig. 8, this is confirmed by [8] that repairs of broken down tractors are expensive. 


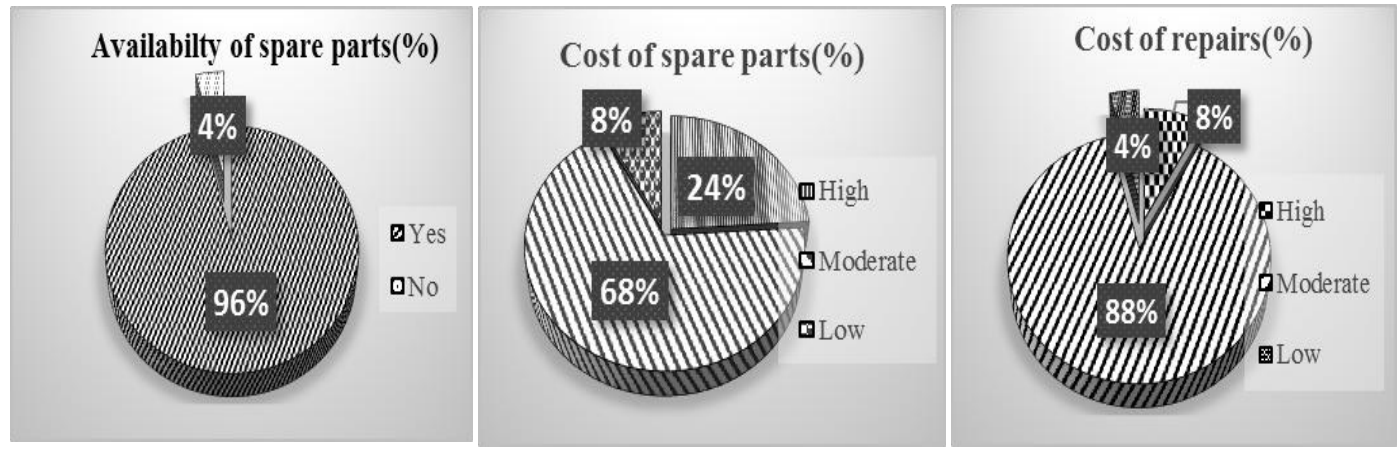

Fig 8: Availability of spare parts, means of obtaining spare parts, cost of spare parts and repairs

\subsection{Guidelines given by GHEL}

Guidelines are mostly given orally by training operators on what to do in order to minimize break downs. It was observed that training the operators is the most effective guideline and are mostly given by the Supervisors. Clients follow guidelines given to them by supervisors and are monitored through regular phone calls as illustrated in Fig. 9 and 10.

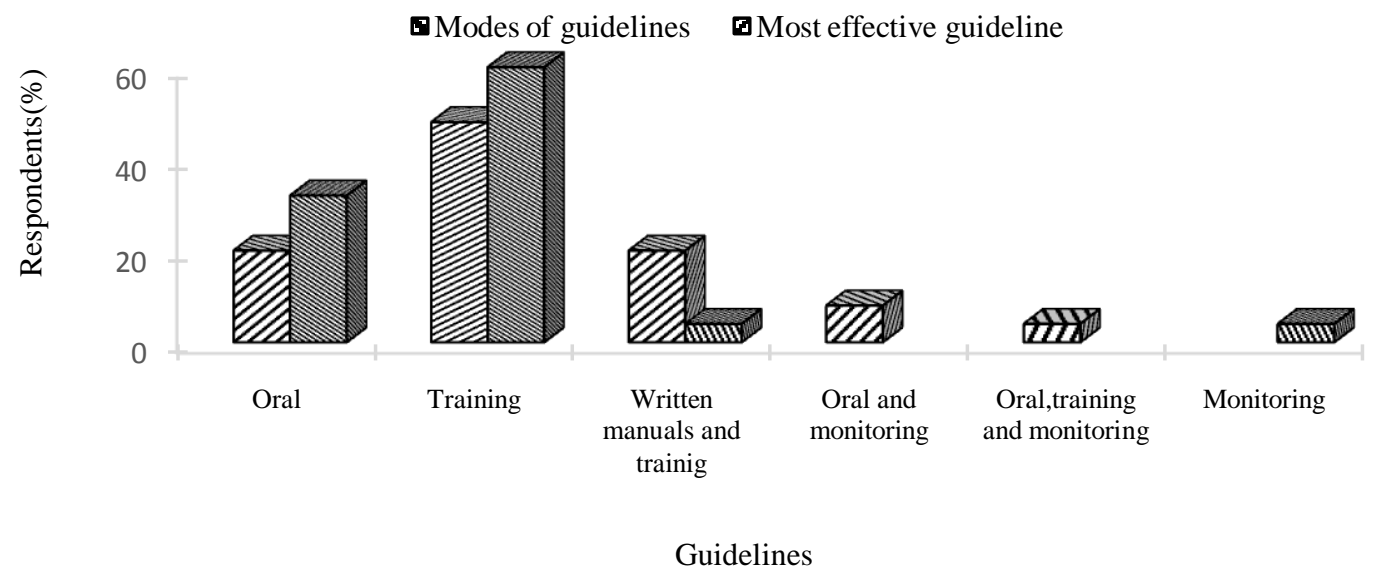

Fig. 9: Modes and most effective guideline given by GHEL

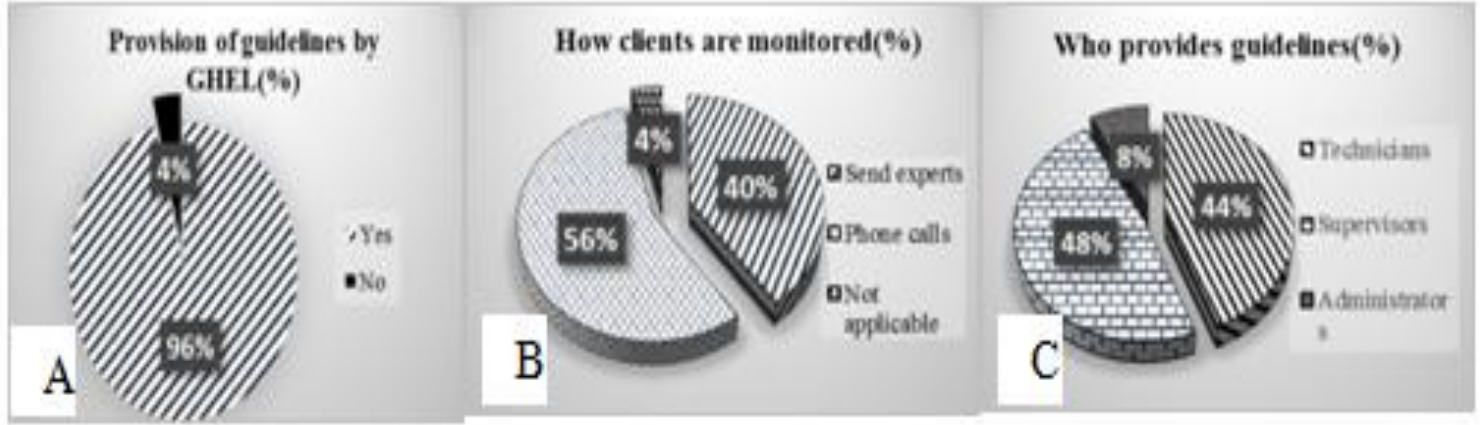

Fig. 10: A; Provision of guidelines, B; How GHEL monitors clients, C; Who provides guidelines

\subsection{Background Information on Job Cards}

Job cards collected at the Accra and Tamale branch of GHEL indicated that there were high number of breakdown in 2009 at Accra whiles 2008 had the highest number of tractors breakdowns in Tamale. It also indicated that tractor breakdowns occurred most within the months of May and August for both branches and this may be due to their use for land preparation during these months. Accra had Zetor 6340 breaking down more frequently whiles Tamale had Zetor
5320 breaking down frequently. It was also observed that tractors were usually brought for servicing within 500-1900 hours of field work as shown in Fig. 11. 

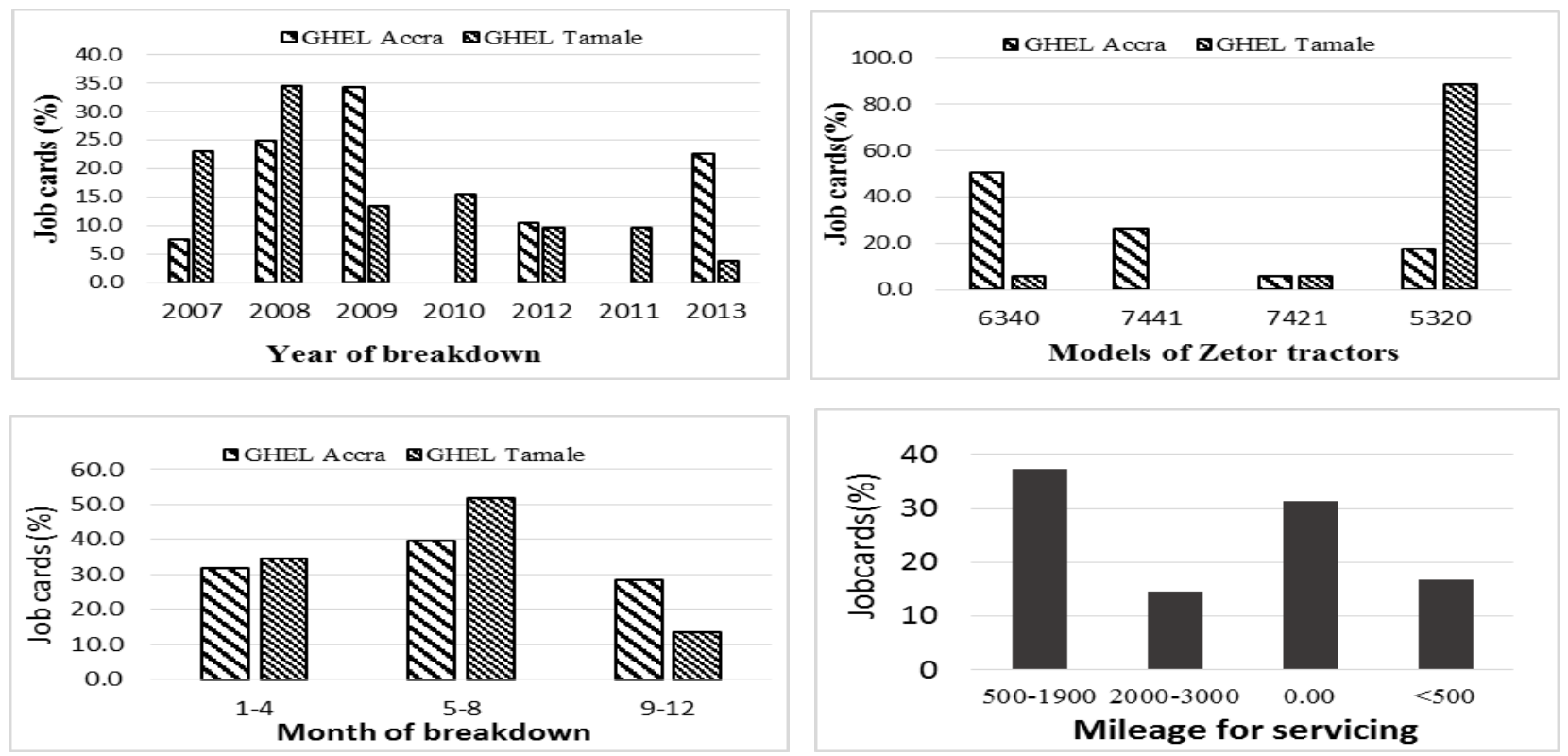

Fig. 11: Year, month and model of tractor with the most breakdown and mileage for servicing

\subsection{Work done and Parts used by Engineers}

Secondary data collected showed that Engineers in GHEL carry out a series of work on tractors and it was observed that servicing of tractors as well as repairs of the braking systems of tractors were mostly carried out in Accra whiles Tamale had servicing and engine overhaul mostly done. Servicing is mostly done in Accra than Tamale. Parts mostly and commonly used by both branches are fuel filter, oil filter and liners. Other parts used are fuel pump, filter element, connecting rod bearing, oil seals and brake cylinder. Results are shown in Fig. 12 and 13.

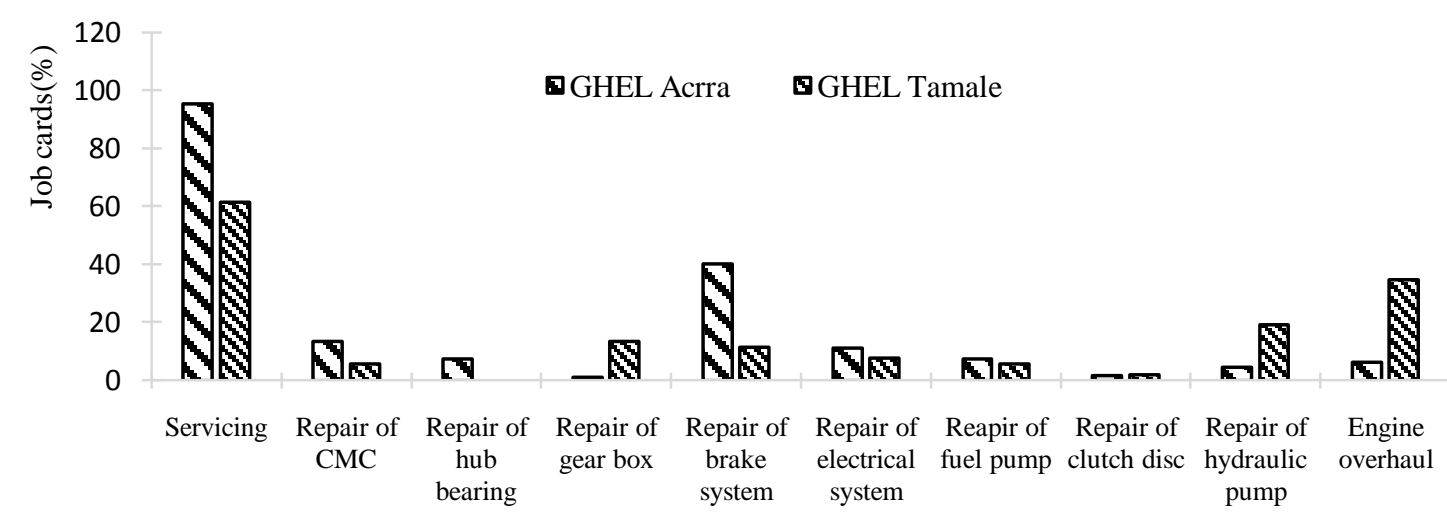

Work carried out by Engineers

Fig. 12: Work carried out by Engineers 


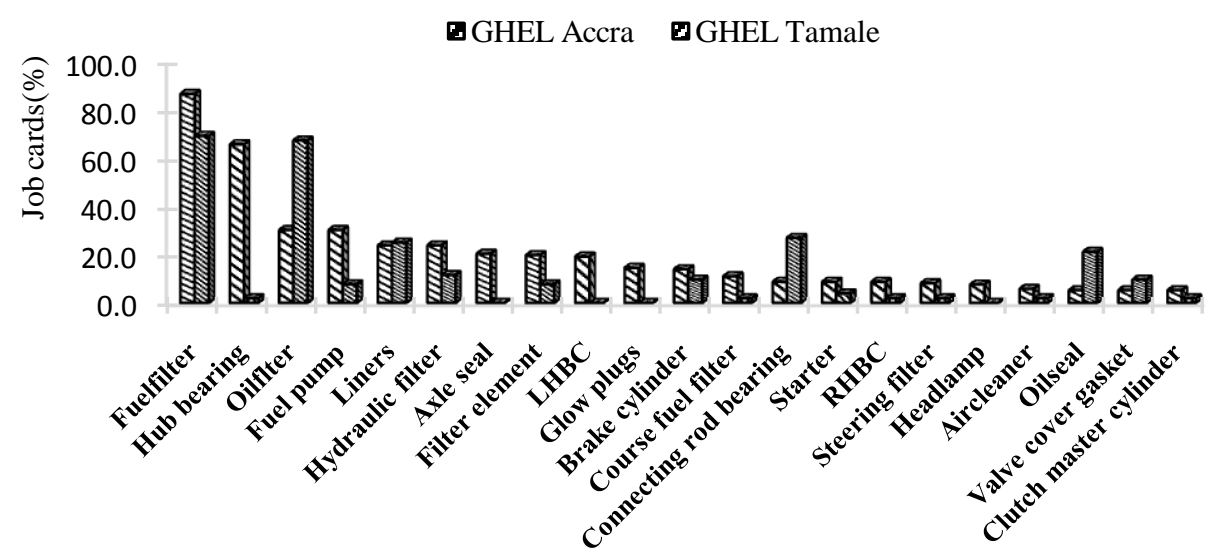

Parts used for servicing and repairs

Fig. 13: Parts used by Engineers for repairs and servicing

\subsection{Cost Associated with Repairs}

Secondary data collected from both branches of the company indicated that cost of labour in Tamale is higher than Accra and this might be due to transportation of parts to Tamale.

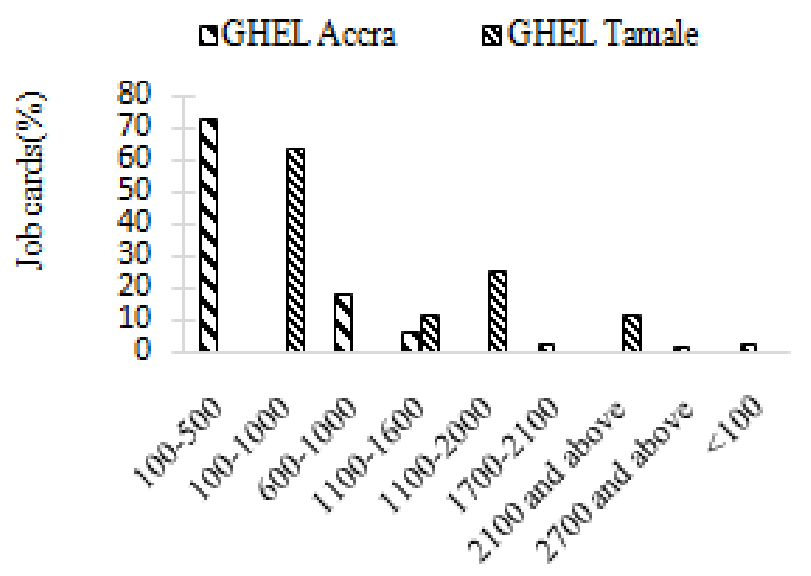

\section{Cost of labour GH(c)}

Fig. 14: Cost of labour

\section{CONCLUSION}

This paper revealed that parts that frequently break down in increasing order are oil seal, clutch master cylinder, hub bearing, clutch system, brake system and clutch port. However fuel and air filters are parts that are regularly changed. Though parts are readily available for the repairs and servicing of Zetor tractors, the cost of these spare parts as well as repairing and servicing are moderately high. Clients of GHEL are able to achieve effectively their training of operator providing them with guidelines. The study thus recommends operators should not over work machine capacity but rather adhere to manufacturers and operators manuals to minimize breakdowns. In addition servicing of tractors should be done regularly to reduce cost of repairs.
Cost of spare parts was no exception as well as the overall charges for services delivered to clients. Results are shown Fig. 14 and 15.

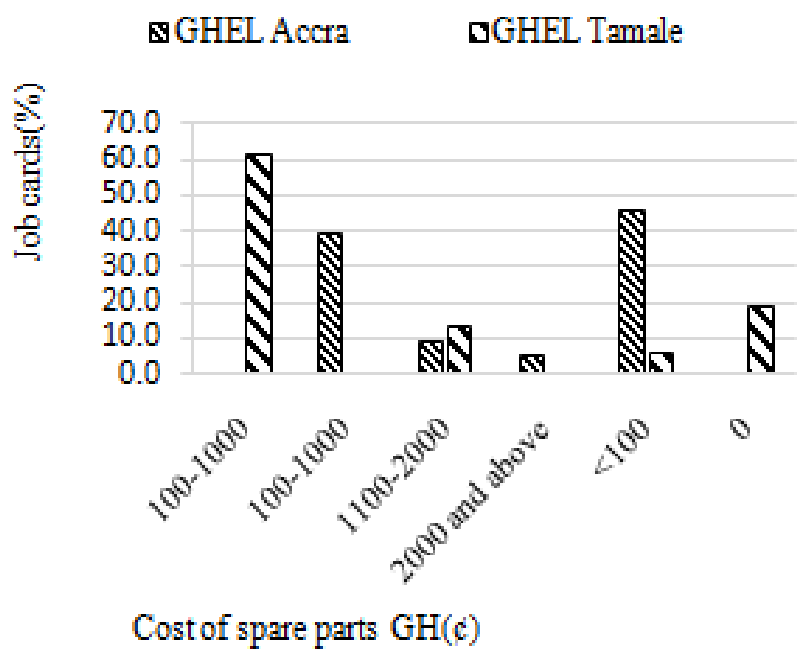

Fig. 15: Cost of spare parts

\section{REFERENCES}

[1]. IFPRI. 2010. Annual Report. Available at: http:// www. ifpri. org/sites/default/files/publi cations/ar 10.pdf [accessed on $11 / 10 / 2013$ ]

[2]. Li, S. 2005. Agricultural Mechanization Promotion in China - Current Situation and Future, Agricultural Engineering International: the CIGR Journal of Scientific Research and Development. Invited Overview Paper, Vol. 7. [3]. Ampratwum, D., Dorvlo, A., Opara, L. 2004. Usage of tractor and field machinery in agriculture in Oman. Agricultural Engineering International: the CIGR Journal of Scientific Research and Development. Invited Overview Paper. Vol. VI. July 2004. 
[4]. Ani, A. O., Onwualu, A. P. 2002. Agricultural mechanization: A Pre-requisite for food security in West Africa. Proc. 1st International Conference of the West African Society of Agricultural Engineering, Abuja, Nigeria. 24-28 Oct. 2002

[5]. Diao, X., J. Thurlow, S. Benin, and Fan, S., 2012. Strategies and Priorities for African Agriculture: Economywide Perspectives from Country Studies. Washington, DC: International Food Policy Research Institute.

[6]. Pingali, P., Bigot,Y., Binswanger, P. H., 1987. Agricultural Mechanization and the Evolution of Farming Systems in Sub-Saharan Africa. Washington, D.C.: The World Bank and Johns Hopkins University Press.

[7]. Jacobs C.O., Harrell W.R., Shinn G.C. 1983. Agricultural power and machinery. New York, McGraw-Hill Inc.

[8]. Hunt D. 1971. Equipment reliability: Indiana and Illinois data. Transactions of the ASAE, 14(5), 742-746.

[9]. Dodson B. 1994. Determining the optimum schedule for preventive maintenance. Quality Engineering, 6(4), 667-679.

[10]. Houssou, N., Diao, X., Cossar, F., Kolavalli, S., Jimah, K., Aboagye, P. 2013. International Food Policy Research Institute: Agricultural Mechanization in Ghana Is Specialization in Agricultural Mechanization a Viable Business Model? Available at: www.ifpri.org [accessed on 10/10/2013].

[11]. Eziakor, E. G. (1990). Comparative Analysis of the Effectiveness of Manual versus Mechanized Tillage among Third-World Smallholders: A case study of the Bauchi State of Nigeria. Agriculture, Ecosystems, and Environment, 31, 301-312.

[12]. Paman, U., Uchida, S., Inabaz, S. 2010. The Economic Potential of Tractor Hire Business in Riau Province, Indonesia: A case of small tractor use for small rice farms. Agricultural Engineering International: the CIGR Ejournal, 12 (1), $135-142$.

[13]. Boamah, J. K. (2006). Policies on Engineering in Agricultural Development. Paper presented at the Third National Biannual Conference of the Ghana Society of Agricultural Engineering, August 2006, Kumasi, Ghana.

[14]. FAO 2011. Agricultural and Food Engineering Technical Report: Investment in agricultural mechanization in Africa. Available at: http://www.fao.org/ag/ags [accessed on $10 / 10 / 2013$ ] 